\title{
Quantitative ultrastructure of the luteal cell of the 16-day-pregnant rat and its relation to progesterone secretion
}

\author{
G. T. Meyer and N. W. Bruce \\ Department of Anatomy and Human Biology, The University of Western Australia, Nedlands, \\ Western Australia 6009, Australia
}

\begin{abstract}
Summary. The ultrastructure of luteal cells of five Day-16 pregnant rats was examined morphometrically to determine the relationship between the quantity of steroidogenic organelles and membranes and reported rates of progesterone secretion $(2 \cdot 3 \mu \mathrm{g} / \mathrm{h})$. Each rat had $11.8 \pm 1.0$ corpora lutea (mean \pm s.e.m.) with an average volume of 4.5 $\pm 0.1 \mu \mathrm{l}$. There were $210000 \pm 10000$ luteal cells per $\mathrm{CL}$ and the luteal cell cytoplasm was composed of smooth endoplasmic reticulum $(18 \%)$, mitochondria $(10.6 \%)$, lipid droplets $(8.9 \%)$ and granules $(0.6 \%)$. The surface area of the smooth endoplasmic reticulum was $192 \mathrm{~cm}^{2}$ per $\mathrm{CL}$, and that of the outer and inner mitochondrial membranes was 20 and $34 \mathrm{~cm}^{2}$, respectively. For each square micrometre of these membranes, respectively, 62, 590 and 355 molecules of progesterone would have been secreted per second. The luteal cell appears to secrete its major steroid hormone at a rate 50 times greater than that reported for the Leydig cell of the testis when secretion is expressed in terms of molecules per unit mass of steroidogenic cell or area of steroidogenic membrane.
\end{abstract}

\section{Introduction}

The development of practical and accurate techniques for quantitating histological characteristics of cells and tissues has led to renewed interest in correlating structure to function in a variety of organs. An underlying objective in this work was to determine whether the physiological activity of an organ or tissue is related to, or is limited by, its structural characteristics. The corpus luteum of the rat is useful for such studies because its functional activity, with respect to progesterone secretion, can be accurately determined and its relatively homogeneous, discrete structure simplifies morphometric analyses.

We have previously examined, at the light microscope level, luteal structure at different stages of gestation in the rat and related this to plasma concentrations of progesterone (Meyer \& Bruce, 1979a, 1980). In the present work the ultrastructure of the luteal cell was examined to relate structural features of those cell organelles considered to be significant in steroid synthesis (Christensen, 1975) with rate of progesterone secretion as determined previously by a venous outflow technique (Bruce \& Meyer, 1981). The study was designed so that the values obtained for luteal cells could be compared with those reported for a similar steroid-secreting cell, the Leydig cell of the rat testis (Mori \& Christensen, 1980). Luteal cells were examined in rats at Day 16 of pregnancy, a time when progesterone secretory activity is normally maximal (Uchida, Kadowaki, Nomura, Miyata \& Miyake, 1970). 


\section{Materials and Methods}

\section{Tissue collection and processing}

Five nulliparous albino Wistar rats, $3-5$ months old and weighing $226 \pm 9 \mathrm{~g}$ (mean \pm s.e.m.) at mating were used. They were kept in an environmentally controlled building; the day on which spermatozoa were found in a vaginal smear was called Day 1 of gestation. On Day 16 each rat was anaesthetized with ether and a blood sample $(0.4 \mathrm{ml})$ was immediately collected from the jugular vein for plasma progesterone measurement. Each rat was then perfused via the aorta with $2.5 \%$ paraformaldehyde $-2 \%$ glutaraldehyde buffered with $0 \cdot 1 \mathrm{M}$-cacodylate buffer, $\mathrm{pH} 7 \cdot 4$, at $90-100$ $\mathrm{mmHg}$ pressure for $20 \mathrm{~min}$ at room temperature. The ovaries were removed, dissected free from associated fat, bursa and oviduct, and weighed. Corpora lutea (CL) were then dissected out and weighed together to determine total luteal mass; the remaining ovarian tissues (stroma) were also weighed. During dissection, tissues were immersed in a combined formaldehyde-glutaraldehyde fixative containing picric acid (Stefanini, De Martino \& Zamboni, 1967). Details of the dissection and weighing (Meyer \& Bruce, 1979a) and progesterone radioimmunoassay techniques (Meyer \& Bruce, 1979b) have been described previously.

One CL was randomly selected from each ovary of 5 rats. It was weighed and sliced into large pieces (approximately $0.5 \mathrm{~mm}^{3}$ ) for light microscopy and small pieces (approximately $0.2 \mathrm{~mm}^{3}$ ) for electron microscopy. A slice from the centre and periphery of each CL was processed and analysed separately. After the dissected tissues had remained in fixative for a further $2 \mathrm{~h}$ they were processed as described previously (Meyer \& Bruce, 1979a) except that dehydration commenced at an ethanol concentration of $75 \%$ rather than $50 \%$.

\section{Tissue examination}

Light microscopy. Thick sections $(0.5 \mu \mathrm{m})$ were cut on an LKB Ultratome with a dry glass knife. Sections were stained with a freshly prepared aqueous solution of $1 \%$ toluidine blue in $1 \%$ borax and examined at a magnification of $\times 1000$ under an Olympus BHC light microscope, fitted with an eyepiece graticule, containing the multipurpose test system M42 (Weibel, 1979; p. 376). One section was examined from a central and a peripheral slice taken from one CL from each ovary of each of the 5 rats. Three fields were analyzed in each section and thus a total of 60 fields were examined in all. The stereological methods used here and in our previous studies (Meyer \& Bruce, $1979 \mathrm{a}, \mathrm{b} ; 1980$ ) were based on the stereological principles and techniques originally described by Weibel \& Gomez (1962) and elaborated by Weibel (1979). The formula used for estimating volume fraction was $V_{v}=P_{p}$, for surface density it was $S_{v}=2 I_{L}$, and for numerical density of nuclei was $\mathrm{N}_{\mathrm{v}}=(K / \beta)\left(\mathrm{N}_{\mathrm{A}}{ }^{3} / \mathrm{P}_{\mathrm{p}}\right)$ (see Weibel, 1979; formulae $2 \cdot 24,2 \cdot 31$ and $2 \cdot 85$, respectively). The size coefficient $K$ was given a value of 1.0 and for luteal cell nuclei, the shape coefficient $\beta$ was given a value of 1.382 which is appropriate for spheres. For the endothelial cell nuclei the $\beta$ coefficient was given a value of $1 \cdot 72$. Although pleiomorphic, these nuclei generally resemble oblate spheroids and the coefficient, based on the measurement of axial ratios of 20 nuclei $(0 \cdot 43 \pm 0 \cdot 04$, mean \pm s.e.m. was estimated graphically (Weibel, 1979; Fig. 2.30).

Electron microscopy. Thin sections of silver interference colour were cut with a glass knife and picked up on clean uncoated 200-mesh copper grids. Sections were stained for 10-20 min with $2 \%$ aqueous magnesium uranyl acetate, and for a further $5 \mathrm{~min}$ with lead citrate. Micrographs were taken on a Philips 300 electron microscope at $80 \mathrm{kV}$. Magnifications were determined by means of a carbon grating replica.

Twenty luteal cells were examined from different tissue blocks: one each from the periphery and centre of one $\mathrm{CL}$ from each ovary of each of the 5 rats. Cells were selected if a nucleus could be seen and if 5 separate areas of cytoplasm could be photographed at low magnification $(\times 2400)$. This ensured that micrographs were taken from near the maximum profile area of the cell. Five low power micrographs ( $\times 18000$ magnification from $\times 2400$ negatives), covering most of the 
cytoplasm, were taken of each luteal cell. These were used to assess volume fraction and numerical density of lipid droplets and a numerical density of mitochondria. Five higher power micrographs ( $\times 51000$ magnification from $\times 5800$ negatives) were taken of separate areas of cytoplasm selected equidistantly from the nucleus to the periphery of each cell but avoiding areas rich in lipid droplets. These were used to assess volume fractions and membrane surface areas in organelles and inclusions other than lipid droplets. Calculation of these values took into account the average volume fraction of lipid found in cytoplasm. As lipid droplets were very uneven in their distribution, their numerical density and volume fraction was estimated from the lower power micrographs which covered about 8 times greater an area.

Morphometric calculations were carried out using methods similar to those described by Mori \& Christensen (1980) and Weibel $(1963,1979)$. At the low magnification a transparent overlay bearing a lattice grid containing 342 test points was placed on each electron micrograph, then the fraction of points occurring within the structure of interest was determined. This count gave the percentage of luteal cell cytoplasm occupied by a particular organelle's volume. The estimation of numerical density for mitochondria and lipid droplets was carried out using the formula described for light microscopy.

At the higher magnification, for the measurement of organelle membrane surface and volume densities, a transparent overlay of the multipurpose test system (M42) was placed over each micrograph. Intersections with pertinent surface contours on the micrograph were recorded as well as the fraction of points lying on the organelles of interest. Surface areas were calculated for smooth endoplasmic reticulum membrane, outer mitochondrial membrane and inner mitochondrial membrane, the latter including the inner envelope and both surfaces of cristae.

\section{Correction for tissue shrinkage}

Luteal volume was calculated by dividing weight of the perfusion fixed tissue by 1.094 , its relative density (Meyer \& Bruce, 1979a). All values were adjusted back to this volume by applying appropriate linear shrinkage factors and assuming shrinkage to be isotropic. The factor for light microscopy $(0.935)$ was determined by dividing the length of a section of tissue measured after processing, cutting and mounting by that measured before processing. An attempt was made to determine a specific shrinkage factor for electron microscopy by multiplying the above factor by the distance between two structures observed on an electron micrograph then dividing by the equivalent distance measured from an adjacent light microscope section. A series of 5 such determinations gave variable results probably due to localized shrinking and stretching of thin sections placed on copper mesh grids and exposed to electron beams. Since a reliable factor could not be determined it was decided to use the light microscope shrinkage factor for all subsequent calculations. Volume fractions or percentage compositions were based on point counting and needed no correction. Numerical density included an estimate of area examined and this area was corrected by dividing it by the square of the shrinkage factor to correspond with the area that would have been covered had shrinkage not occurred. Surface density included an estimate of grid line length and this was divided by the shrinkage factor for the same reason.

\section{Correction for shape, size and section thickness (electron microscopy)}

To estimate the numerical density of lipid droplets, $K$ was given a value of 1.0 and $\beta$, a value of $1 \cdot 382$, that for spheres. Mitochondria were assumed to be cylindrical in shape and from their average axial ratio a $\beta$ coefficient value of 1.9 was assigned (Weibel, 1979; Fig. 2.30). The $K$ coefficient for mitochondria was again given a value of $1 \cdot 0$.

Volume fraction and surface density values tend to be overestimated due to factors relating to shape and size of structures relative to section thickness. Appropriate correction factors were determined using the methods and sets of curves described originally by Weibel \& Paumgartner 
(1978). In this study, mitochondria and smooth endoplasmic reticulum were assumed to be cylindrical, lipid droplets and granules to be spherical, and section thickness to be $40 \mathrm{~nm}$. The multipurpose test grid was used on the high magnification electron micrographs $(\times 51000)$ to select sites for measuring critical width of structures (Weibel \& Paumgartner, 1978). Whenever a test line intersected a profile of tubules or cristae the diameter (d) was measured if the bounding membranes were sharp, indicating that the profile was cut about perpendicularly. Forty measurements were recorded for each component. The tubule length (L) was estimated from the length of 'straight' profiles in the network of tubules. The final correction factors obtained from the sets of curves (Weibel, 1979 ; Figs 4.19 and 4.21 ) and used in the analysis were: for volume density, $K_{t}\left(V_{v}\right)=0.92$, $0.65,0.94$ and 0.81 for mitochondria, smooth endoplasmic reticulum, lipid droplets and granules, respectively; for surface density, $K_{\mathrm{t}}\left(\mathrm{S}_{\mathrm{v}}\right)=0.95,0.95,0.61$ and 0.72 for outer and inner mitochondrial membranes, cristae and smooth endoplasmic reticulum, respectively.

\section{Results}

The number of live fetuses per rat was $11.6 \pm 2 \cdot 4$ (mean \pm s.e.m.) and the number of corpora lutea was $11.8 \pm 1.0$. These values and the mean plasma concentration of progesterone $(85.4 \pm 7.5$ $\mathrm{ng} / \mathrm{ml}$ ) were within the normal range of the colony.

\section{Structure of the corpus luteum}

Ovarian tissue weights and histological data at the light microscopic level are given in Table 1. The central and peripheral sections from each $C L$ were analysed separately but since comparison by paired $t$ tests revealed no significant differences, only the pooled results are shown. Luteal cells made up the greatest percentage of the CL $(66.5 \%)$, together occupying a volume of $35 \mu 1$ per rat. Vessel space, which included vascular, perivascular and lymphatic spaces, occupied $26.4 \%$ of the $\mathrm{CL}$ volume or about $15 \mu \mathrm{l}$ per rat. The remainder of the $\mathrm{CL}$ was made up of connective tissue elements $(3 \cdot 1 \%)$ and endothelial cell nuclei $(4.0 \%)$. There were, on average, $210 \times 10^{3}$ luteal cells

Table 1. Ovarian tissue weights and quantitative histology of the corpus luteum of Day-16 pregnant rats

\begin{tabular}{lr}
\hline Ovarian tissue weights $(\mathrm{mg})$ & \\
$\quad$ Total ovary & $48 \cdot 5 \pm 5 \cdot 0$ \\
Stromal tissue & $20 \cdot 1 \pm 3 \cdot 1$ \\
Luteal tissue & $28 \cdot 4 \pm 2 \cdot 3$ \\
Corpus luteum & $4 \cdot 8 \pm 0 \cdot 1$ \\
Corpus luteum volume $(\mu \mathrm{l})$ & $4 \cdot 5 \pm 0 \cdot 1$ \\
Composition of corpus luteum $(\%)$ & \\
$\quad$ Luteal cells & $66 \cdot 5 \pm 2 \cdot 7$ \\
Vessel space & $26 \cdot 4 \pm 1 \cdot 7$ \\
Connective tissue & $3 \cdot 1 \pm 1 \cdot 3$ \\
Endothelial cell nuclei & $4 \cdot 0 \pm 1 \cdot 3$ \\
Luteal cell volume (pl) & \\
Total & $14.3 \pm 0 \cdot 7$ \\
Nucleus & $0 \cdot 7 \pm 0 \cdot 1$ \\
Cytoplasm & $13.6 \pm 0 \cdot 7$ \\
No. of cells per CL $\left(\times 10^{3}\right)$ & \\
Luteal & $210 \pm 10$ \\
Endothelial & $917 \pm 63$ \\
Surface area of vessels per CL $\left(\mathrm{mm}^{2}\right)$ & $339 \pm 12$ \\
\hline
\end{tabular}

Values given are the group means \pm s.e.m., derived from a single mean value calculated for each rat $(\mathrm{N}=5)$. 


\section{PLATE 1}
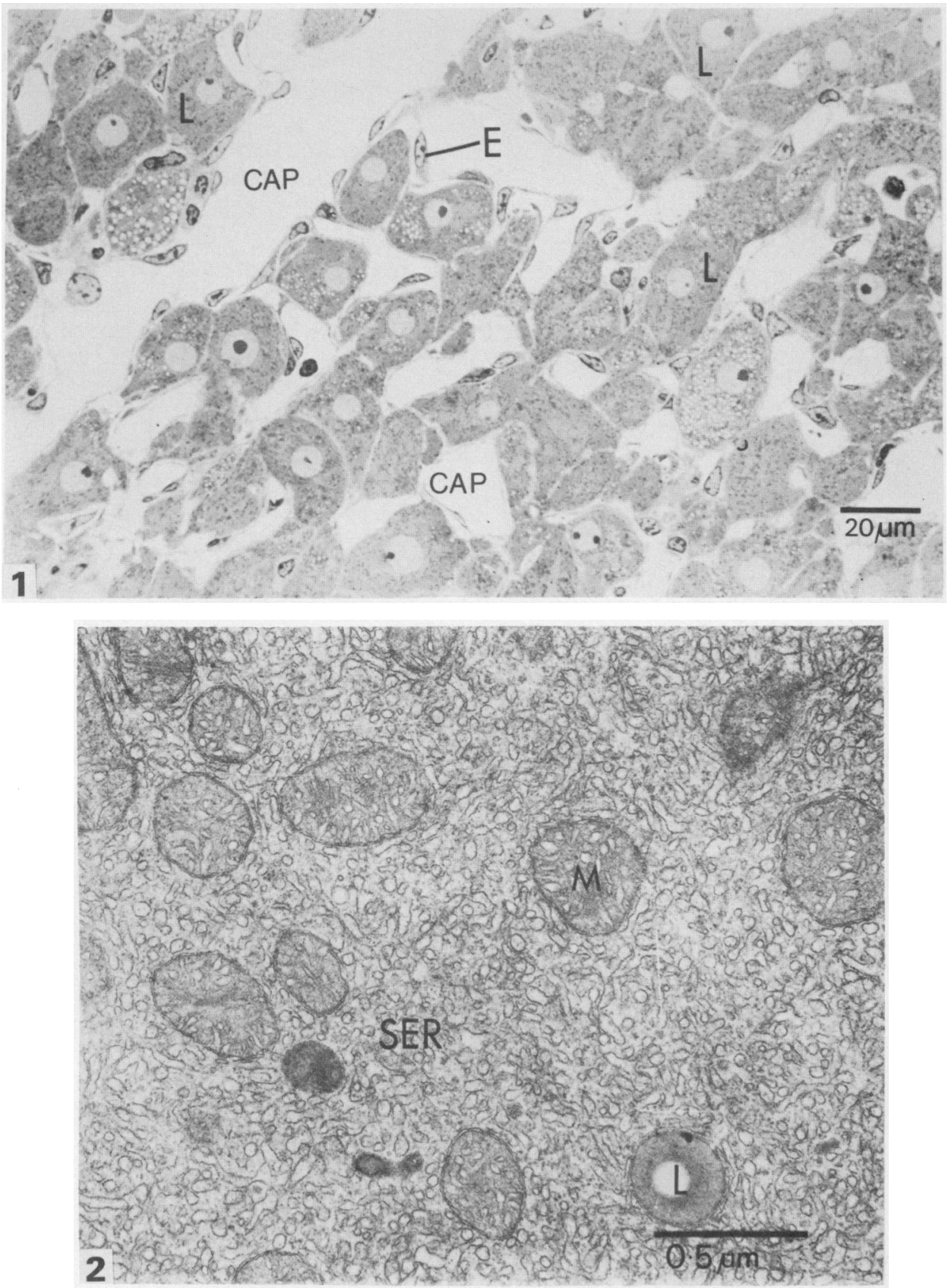

Fig. 1. Light photomicrograph of a $0.5 \mu \mathrm{m}$ section of luteal tissue from a Day-16 pregnant rat. The luteal cells $(\mathrm{L})$ contain a spherical nucleus with one or two prominent nucleoli. There are accumulations of lipid droplets within some of the luteal cells. The luteal tissue has an extensive capillary network (CAP). Endothelial cell nuclei (E) are prominent adjacent to the capillary lumen. $\times 625$.

Fig. 2. Electron micrograph of a portion of luteal cell cytoplasm. The mitochondria (M) and smooth endoplasmic reticulum (SER) are the major steroidogenic organelles and occupy much of the cytoplasm. A lipid droplet (L) can be seen. $\times 48000$. 
PLATE 2

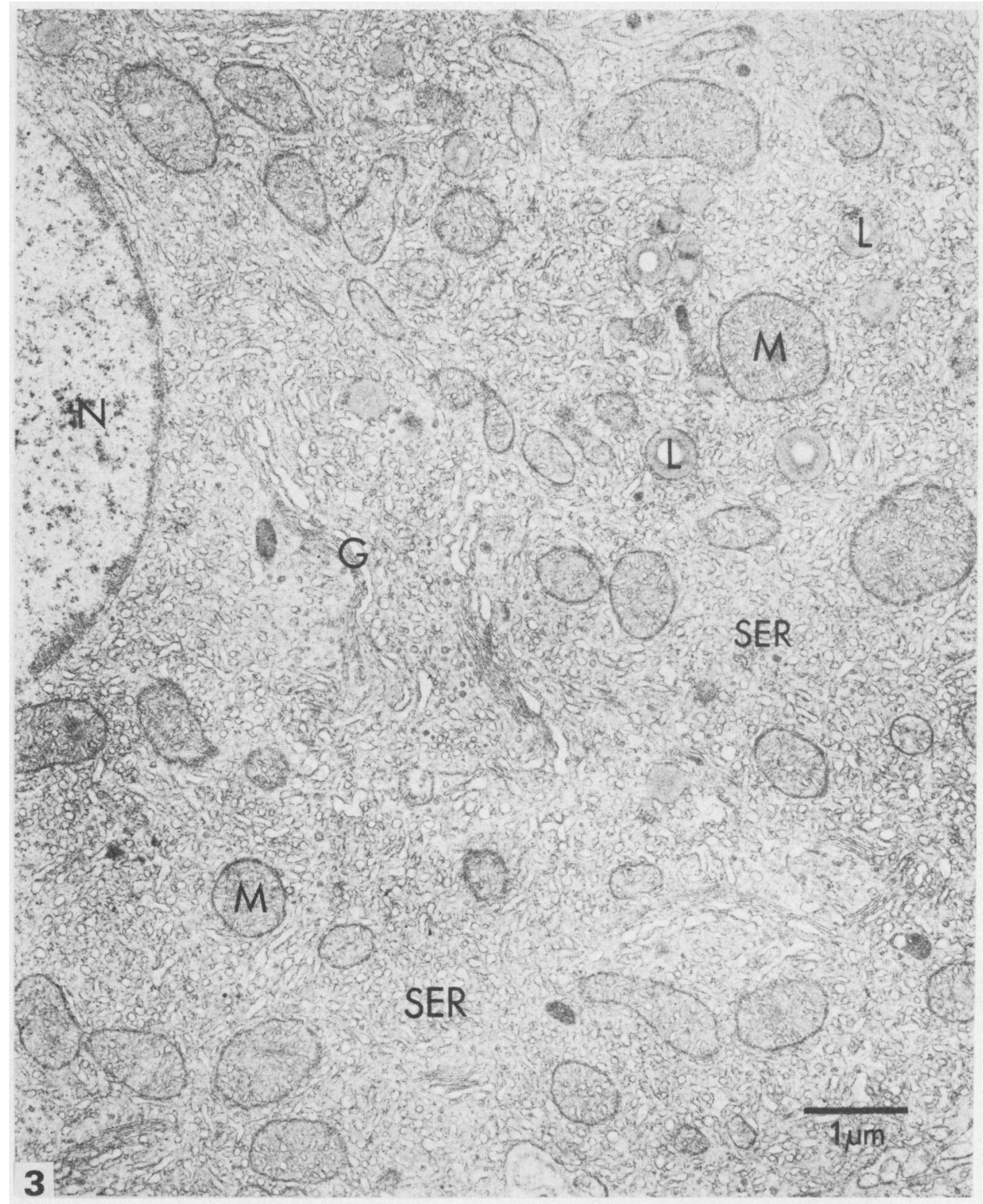

Fig. 3. Electron micrograph of a portion of a luteal cell from a rat at Day 16 of gestation. Part of the cell nucleus $(\mathrm{N})$ is present. The cytoplasm contains many tubular profiles of smooth endoplasmic reticulum (SER), mitochondria (M) with predominantly tubular cristae, lipid droplets (L) and Golgi complexes (G). × 16500 . 
per CL or about $2.48 \times 10^{6}$ cells per rat. The number of endothelial cells was approximately $917 \times$ $10^{3}$ per CL. Luteal cell nuclei were predominantly spherical (see Pl. 1, Fig. 1), had an average volume of $0.7 \mathrm{pl}$ and occupied about $5 \%$ of cell volume. Total volume of the luteal cell was $14.3 \mathrm{pl}$ which, presuming a spherical shape, would be associated with a cell diameter of $30 \cdot 1 \mu \mathrm{m}$.

\section{Ultrastructure of the luteal cell}

Morphometric data on the major cell organelles involved in progesterone synthesis (see Pl. 1, Fig. 2; Pl. 2, Fig. 3) are shown in Table 2. Electron micrographs from the 5 areas of cytoplasm selected equidistantly from the nucleus to the periphery of each cell were analysed separately but since comparison by two-way analysis of variance revealed no significant differences, only the pooled results are shown. The smooth endoplasmic reticulum (SER), including membrane plus contents, was the most abundant organelle occupying $18.4 \%$ of cytoplasmic volume. The membrane surface area of the SER was about $92000 \mu \mathrm{m}^{2}$ per cell or about $192 \mathrm{~cm}^{3}$ per CL. The membranes of the Golgi complex were included with the membranes of the smooth endoplasmic reticulum since they are difficult to distinguish from the latter in oblique sections and are relatively scarce (Mori \& Christensen, 1980).

Table 2. Quantitative ultrastructure of the luteal cell of Day-16 pregnant rats

\begin{tabular}{lc}
\hline Composition of cytoplasm (volume \%) & \\
Cytosol & $61 \cdot 1 \pm 2.5$ \\
Smooth endoplasmic reticulum & $18.4 \pm 1 \cdot 3$ \\
Mitochondria & $10 \cdot 6 \pm 1 \cdot 3$ \\
Lipid droplets & $8.9 \pm 1.8$ \\
Granules & $0.6 \pm 0.2$ \\
No. of mitochondria & $304 \pm 26$ \\
per pl cytoplasm & 4125 \\
per cell & \\
No. of lipid droplets & $135 \pm 15$ \\
per pl cytoplasm & 1831 \\
per cell & \\
Surface area of membranes & \\
Smooth endoplasmic reticulum \\
$\mu \mathrm{m}^{2} / \mu \mathrm{m}^{3}$ cytoplasm \\
$\mu \mathrm{m}^{2} /$ cell & $6.76 \pm 0.51$ \\
$\mathrm{Outer} \mathrm{mitochondrial} \mathrm{membrane}_{\mu \mathrm{m}^{2} / \mu \mathrm{m}^{3} \text { cytoplasm }}$ & 91733 \\
$\mu \mathrm{m}^{2} /$ cell & $0.71 \pm 0.04$ \\
Inner mitochondrial membrane & 9635 \\
$\mu \mathrm{m}^{2} / \mu \mathrm{m}^{3}$ cytoplasm & $1 \cdot 18 \pm 0.05$ \\
$\mu \mathrm{m}^{2} /$ cell & 16013 \\
\hline
\end{tabular}

Values given are the group means \pm s.e.m., derived from a single mean value calculated for each rat $(\mathrm{N}=5)$.

Mitochondria occupied $10.6 \%$ of the cytoplasmic volume and there was an an average of 4125 mitochondria per cell. The surface area of their outer membrane was $9635 \mu \mathrm{m}^{2}$ per cell or $20 \mathrm{~cm}^{2}$ per CL. The surface area of the inner mitochondrial membrane, including cristae, was $16013 \mu \mathrm{m}^{2}$ per cell or $34 \mathrm{~cm}^{2}$ per CL and the cristae amounted to $6378 \mu \mathrm{m}^{2}$ or about $25 \%$ of the total mitochondrial membrane surface area.

Lipid droplets made up $8.9 \%$ of cytoplasmic volume and each cell contained an average of 1831 droplets. However, the amount of lipid appeared to vary considerably between cells and even within cells the distribution of lipid droplets was very uneven. Densely staining, membrane-bound granules appeared to be relatively evenly distributed in the cytoplasm and occupied about $0.6 \%$ by 
volume. Rough endoplasmic reticulum was not observed in all cells but from independent measurements carried out on 14 cells, occupied less than $0.6 \%$ of the total cytoplasm.

\section{Discussion}

The major aim of the present study was to obtain quantitative data on organelles thought to be important in steroid hormone production by the ovary. Steroid secreting cells from the adrenal cortex (Rohr et al., 1976), ovary (Enders, 1973; Long, 1973) and testis (Mori \& Christensen, 1980; Zirkin, Ewing, Kromann \& Cochran, 1980) have many ultrastructural characteristics in common but whether there is a common pattern in the quantitative relationship of ultrastructure to rate of hormone secretion is not known. The extensive study by Mori \& Christensen (1980) has established quantitative relationships for Leydig cell ultrastructure and rate of testosterone secretion in the rat. This presents an ideal comparison for the present work on the luteal cell (Table 3). Values for the testis were derived from sexually mature rats, and those for the ovary from rats at Day 16 of gestation, a time of maximal progesterone secretory activity. There were some differences in techniques used but these are insignificant compared to gross differences in the results obtained. Calculated values are based on the assumption that only Leydig and luteal cells are secreting steroid hormones and the only hormones secreted are testosterone and progesterone, respectively.

Table 3. Comparison of structural and functional relationships in steroidogenic tissue of the rat* testis (adult) and ovary (Day 16 of gestation)

\begin{tabular}{|c|c|c|}
\hline Organ & Testis & Ovary \\
\hline $\begin{array}{l}\text { Steroidogenic cell } \\
\text { Major hormone secreted } \\
\text { Organ weight (mg) }\end{array}$ & $\begin{array}{l}\text { Leydig cell } \\
\text { Testosterone } \\
1600\end{array}$ & $\begin{array}{l}\text { Luteal cell } \\
\text { Progesterone } \\
48\end{array}$ \\
\hline $\begin{array}{l}\text { Steroidogenic cells } \\
\text { Percent organ weight } \\
\text { Total weight }(\mathrm{mg}) \\
\text { Cell volume }(\mathrm{pl}) \\
\text { Cell diameter }(\mu \mathrm{m}) \\
\text { Nucleus:cell volume ratio }(\%)\end{array}$ & $\begin{array}{c}2 \cdot 8 \\
44 \cdot 8 \\
1 \cdot 21 \\
13 \cdot 2 \\
12 \cdot 4\end{array}$ & $\begin{array}{l}40 \\
18 \cdot 9 \\
14 \cdot 3 \\
30 \cdot 1 \\
4 \cdot 9\end{array}$ \\
\hline $\begin{array}{l}\text { Composition of cytoplasm }(\%) \\
\text { Smooth endoplasmic reticulum } \\
\text { Mitochondria } \\
\text { Lipid droplets }\end{array}$ & $\begin{array}{r}13 \cdot 0 \\
12 \cdot 9 \\
0 \cdot 2\end{array}$ & $\begin{array}{r}18 \cdot 4 \\
10 \cdot 6 \\
8 \cdot 9\end{array}$ \\
\hline $\begin{array}{l}\text { Membrane surface area } \\
\left(\mu \mathrm{m}^{2} / \mu \mathrm{m}^{3} \text { cytoplasm }\right) \\
\text { Smooth endoplasmic reticulum } \\
\text { Outer mitochondrial membrane } \\
\text { Inner mitochondrial membrane }\end{array}$ & $\begin{array}{l}9 \cdot 9 \\
1 \cdot 5 \\
2 \cdot 8\end{array}$ & $\begin{array}{l}6.8 \\
0.7 \\
1 \cdot 2\end{array}$ \\
\hline $\begin{array}{l}\text { Steroid secretion } \\
\mu \mathrm{g} / \mathrm{gonad} \text { per hour } \\
\mathrm{ng} / \mathrm{g} \text { steroid cells per min } \\
\mathrm{p} \text { mol/g steroid cells per min } \\
\text { molecules } / \mu \mathrm{m}^{2} \text { membrane per sec } \\
\text { Smooth endoplasmic reticulum } \\
\text { Outer mitochondrial membrane } \\
\text { Inner mitochondrial membrane }\end{array}$ & $\begin{array}{l}0.65 \\
2.39 \times 10^{2} \\
8.21 \times 10^{2} \\
1.0 \\
6.4 \\
3.6\end{array}$ & $\begin{array}{c}13 \cdot 7 \\
1.6 \times 10^{4} \\
5 \cdot 1 \times 10^{4} \\
62 \cdot 0 \\
590 \\
355 \cdot 3\end{array}$ \\
\hline
\end{tabular}

* Testicular morphometry values adapted from Mori \& Christensen (1980), testosterone secretion from Free \& Tillson (1973). Ovarian morphometry values are taken directly from the present work and progesterone secretion from Bruce \& Meyer (1981). 
The testis is 33 times heavier than the ovary but only a small percentage of testicular volume is composed of Leydig cells and so total steroidogenic mass is only 2-4 times greater. At the light microscope level the most obvious difference is the relatively small volume of the Leydig cell, $8.4 \%$ that of the luteal cell, a difference which is difficult to appreciate from qualitative assessments based on cell diameter alone. Even on Day 1 of gestation within a few hours of ovulation, luteal cell volume, $2 \cdot 1 \mathrm{pl}$ (value taken from Meyer \& Bruce (1980) and adjusted for shrinkage), is $77 \%$ larger than the mature Leydig cell. Luteal cells hypertrophy to about 7 times their original volume by Day 16 and seem capable of still further hypertrophy, but not hyperplasia, in response to unilateral ovariectomy (Meyer \& Bruce, 1982). In contrast, Leydig cell hypertrophy seems to be limited although total number can increase by a factor of 3 following chronic hCG stimulation of the adult testis (Christensen \& Peacock, 1980). It is possible that structural or functional limitations to growth are quite different in the two cell types, despite other apparent similarities. Absolute nuclear volume in the Leydig cell is only about $21 \%$ of that in the luteal cell, although when expressed as a percentage of cell volume it is substantially greater. Nuclear volume is related to steroid secretion rates, at least in luteal cells (Meyer \& Bruce, 1979a), but whether this relationship is functionally significant is not known.

The percentage composition of cytoplasm is similar in the two cell types except for the relatively small amount of lipid droplets in the Leydig cell, less than $3 \%$ of that in the luteal cell. Mori \& Christensen (1980) have pointed out that Leydig cells of adult laboratory rats characteristically contain very few lipid droplets compared with Leydig cells of the mouse, guinea-pig, human and various other species, and suggest that they store little of the cholesterol they synthesize. On the other hand, if lipid droplets are considered as a cholesterol store, and since rate of steroid secretion per gram of steroidogenic cells is 67 times greater in the ovary, then the volume of the cholesterol store per steroid molecule secreted would be similar for the two gonads. The chemical composition and function of lipid droplets in steroidogenic cells is not fully known. There seems to be a discrepancy between the chemical determination of cholesterol $(1.07 \%$ of CL weight; Uchida et al., 1970 ) and the volumetric estimate of lipid droplets, which are thought to be mainly composed of cholesterol esters $(5.62 \%$ of CL volume, as determined here). It would be interesting to determine the precise chemical ratio between cholesterol ester stores and rate of steroid secretion in the two gonads.

The most obvious functional difference between the testis and the ovary is that hormone secretion, per unit mass of steroidogenic cell, is 67 times greater in the latter. The organelles and surface area of membranes considered to be important to steroid secretion are similar in the two gonads. Therefore, secretion expressed as molecules per unit area of membrane is greater in the ovary by a factor of from 62 for SER, to 99 for inner mitochondrial membranes. These extreme differences were quite unexpected and demand further investigation. The fact that different steroidogenic cell types have a characteristic ultrastructure is often used to suggest that they have similar structural-functional relationships. A striking example of such a relationship is the finding of a 0.99 correlation between SER in the Leydig cell and testosterone secretion per mass of Leydig cell in 5 mammalian species (Zirkin et al., 1980). In the present work, however, when comparing different steroidogenic tissues (i.e. testis and ovary) within the same species structural-functional relationships are markedly dissimilar. A number of possible explanations however, can be offered.

First, the similarity of steroidogenic cell ultrastructure could be coincidental and masks real differences in metabolic pathways of steroid synthesis. For example, although cholesterol is a common precursor in the synthesis of both progesterone and testosterone, there is some debate as to whether it is taken up directly from arterial blood or synthesized from acetate within the cell. The latter mechanism seems to be important in the testis (van der Molen \& Rommerts, 1981), but not in the ovary (Swann \& Bruce, 1982). It is feasible that synthesis of cholesterol from acetate involves a significant proportion of the Leydig cell organelles and so explains the relatively low rate of hormone secretion per surface area of steroidogenic membrane. 
Secondly, the above calculations were based on the assumption that testosterone and progesterone are the only hormones secreted by the testis and ovary respectively. The testes of mature rats do produce other steroid hormones, for example the testicular secretion of $7 \alpha$-hydroxytestosterone can be as high as that of testosterone (van der Molen \& Rommerts, 1981) and the rat ovary secretes $20 \alpha$-dihydroprogesterone at a rate of about $30 \%$ that of progesterone (Uchida et al., 1970). To date, however, there is no indication that the secretion of hormones, other than testosterone and progesterone, is sufficient to explain the gross difference in structural-functional relationships between the two gonads.

Thirdly, the steroid secretion rates used in the above calculations refer to their secretion into the venous drainage system alone and not to total rate of steroid synthesis by the gonad. In the testis there is good evidence that some of the testosterone synthesized is either taken up by the seminiferous tubules, leaves by the lymphatics, or is metabolized within the gonad (van der Molen \& Rommerts, 1981). Less is known about the fate of progesterone synthesized in the rat ovary, although in the sheep it is estimated that around $10 \%$ might leave by the lymphatics (Morris \& Sass, 1966). Quantitative estimates of the significance of alternate routes of secretion or metabolism of hormones within the gonad are not available but again it is highly unlikely that they could explain the greater than $50: 1$ difference in the rate of hormone secretion per unit area of steroidogenic membrane between the two gonads.

Finally, it is possible that the physiological reserve or capacity for increased steroid secretion is much greater in the testis than in the ovary, but information is not available on maximum rate determined from rats maintained under physiological conditions.

Whatever the explanation, the present work, together with the pioneering study of Mori \& Christensen (1980), clearly shows that cells with similar secretory products and quantitative ultrastructural characteristics can have greatly different structural-functional relationships. For the quantitative histological approach to succeed, more information is needed on the biochemistry of hormone synthesis under normal physiological conditions in different steroidogenic tissues. Bringing together such information should provide a new dimension to the understanding of the cell biology of steroid hormone secretion.

We are grateful for the advice of Dr W. F. C. Blumer and the expert technical assistance of Mr S. Parkinson and Mr P. Burton. Financial support was received from the Australian Research Grants Council. G.T.M. was supported by a University of Western Australia Research Studentship during his Ph.D. Candidature.

\section{References}

Bruce, N.W. \& Meyer, G.T. (1981) Ovarian blood flow and progesterone secretion in anaesthetized rats at Day 16 of gestation, and the effects of haemorrhage. J. Reprod. Fert. 61, 419-423.

Christensen, A.K. (1975) Leydig cells. In Handbook of Physiology, Section 7, Vol. 5, pp. 57-94. Eds D. W. Hamilton \& R. O. Greep. Am. Physiol. Soc., Washington, D.C.

Christensen, A.K. \& Peacock, K.C. (1980) Increase in Leydig cell number in testes of adult rats treated chronically with an excess of human chorionic gonadotropin. Biol. Reprod. 22, 383-391.

Enders, A.C. (1973) Cytology of the corpus luteum. Biol. Reprod. 8, 158-182.

Free, M.J. \& Tillson, S.A. (1973) Secretion rate of testicular steroids in the conscious and halothaneanesthetized rat. Endocrinology 93, 874-879.
Long, J.A. (1973) Corpus luteum of pregnancy in the rat-ultrastructural and cytochemical observations. Biol. Reprod. 8, 87-99.

Meyer, G.T. \& Bruce, N.W. (1979a) The cellular pattern of corpus luteum growth during pregnancy in the rat. Anat. Rec. 193, 823-830.

Meyer, G.T. \& Bruce, N.W. (1979b) Corpus luteum growth and plasma progesterone levels in unilaterally ovariectomized pregnant rats. Anat. Rec. 195, 311316.

Meyer, G.T. \& Bruce, N.W. (1980) Quantitative cell changes and vascularisation in the early corpus luteum of the pregnant rat. Anat. Rec. 197, 369-374.

Meyer, G.T. \& Bruce, N.W. (1982) Rate of ovarian progesterone secretion and peripheral plasma progesterone levels in unilaterally ovariectomized pregnants rats. J. Reprod. Fert. 66, 555-561. 
Mori, H. \& Christensen, A.K. (1980) Morphometric analysis of Leydig cells in the normal rat testis. $J$. Cell Biol. 84, 340-354.

Morris, B. \& Sass, M.B. (1966) The formation of lymph in the ovary. Proc. R. Soc. Lond. B 164, 577-591.

Rohr, H.P., Bartsch, G., Eichenberg, P., Rasser, Y., Kaiser, Ch. \& Keller, M. (1976) Ultrastructural morphometric analysis of the unstimulated adrenal cortex of rats. J. Ultrastruct. Res. 54, 11-21.

Stefanini, M., De Martino, C. \& Zamboni, L. (1967) Fixation of ejaculated spermatozoa for electron microscopy. Nature, Lond. 216, 173.

Swann, R.T. \& Bruce, N.W. (1982) The importance of acetate as a precursor of progesterone in the rat ovary. Proc. 14th A. Conf. Aust. Soc. Reprod. Biol., Abstr. 24.

Uchida, K., Kadowaki, M., Nomura, Y., Miyata, K. \& Miyake, T. (1970) Relationship between ovarian progestion and corpora lutea function in pregnant rats. Endocr. Jap. 17, 499-507.

van der Molen, H.J. \& Rommerts, F.F.G. (1981) Testicular steroidogenesis. In The Testis, pp. 213-238. Eds H. Burger \& D. de Kretser. Raven Press, New York.
Weibel, E. R. (1963) Morphometry of the Human Lung. Springer, Berlin.

Weibel, E.R. (1979) Stereological Methods. Vol. 1, Practical Methods for Biological Morphometry. Academic Press, London.

Weibel, E.R. \& Gomez, D.M. (1962) A principle for counting tissue structures on random sections. J. appl. Physiol. 17, 343-348.

Weibel, E.R. \& Paumgartner, D. (1978) Integrated stereological and biological studies on hepatocytic membranes. II. Correction of section thickness effect on volume and surface density estimates. J. Cell Biol. 77, 584-597.

Zirkin, B.R., Ewing, L.L., Kromann, N. \& Cochran, R.C. (1980) Testosterone secretion by rat, rabbit, guinea pig, dog and hamster testes perfused in vitro: correlation with Leydig cell ultrastructure. Endocrinology $107,1867-1874$.

Received 7 June 1983 